\title{
Assessment of association between variants and haplotypes of the remaining TBX1 gene and manifestations of congenital heart defects in $22 q 11.2$ deletion patients
}

\author{
A Rauch, K Devriendt, A Koch, R Rauch, M Gewillig, C Kraus, M Weyand, H Singer, A Reis, \\ $M$ Hofbeck
}

D eletion 22q11.2, commonly associated with DiGeorge or velocardiofacial syndrome (DGS/VCFS; MIM 188400), is a major cause of congenital heart disease, accounting for about $5 \%$ of all congenital heart defects in live births. However, the presence of the deletion does not allow one to predict the phenotype, as patients with a $22 \mathrm{ql} 1.2$ deletion usually show a broad range of clinical variation despite a common deletion size of $3 \mathrm{Mb}^{2}{ }^{2}$ Observations of phenotypic discordance-especially in the heart manifestations-in monozygotic twins concordant for $22 q 11.2$ deletion have led some investigators to postulate that the clinical variability in this disorder is generally not caused by genetic factors. ${ }^{3-8}$ Nevertheless, studies of Dfl/t mice, which model the 22q11.2 deletion from Tbxl haploinsufficiency, showed that the penetrance of cardiovascular defects varies widely in different genetic backgrounds, thus revealing for the first time the presence of major genetic control over the phenotypic

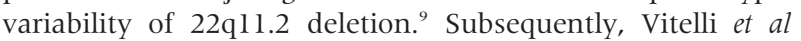
showed that $\mathrm{TbxI}{ }^{+/-} ; \mathrm{Fgfs}^{+/-}$double mutants present with a significantly higher penetrance of aortic arch artery defects than $\mathrm{TbxI}^{+/-} ; \mathrm{Fgfl}^{+/+}$mutants, while $\mathrm{TbxI}^{+/+} ; \mathrm{Fgfl}^{+/-}$animals are normal. ${ }^{10}$ The underlying mechanism in humans is still unclear, however. There is no evidence for an imprinting effect, and we previously excluded somatic second hit deletions in tissues derived from the pharyngeal arch as a common mechanism for the clinical variability with respect to congenital heart disease ${ }^{11}$ Recently, a preliminary association between the expression of congenital heart defects in 22q11.2 deletion patients and a certain single nucleotide polymorphism (SNP) haplotype within the promotor region of VEGF was reported. ${ }^{12}$ However, apart from non-allelic modifiers, unmasking of recessive mutations by hemizygosity has also been considered a possible modifying factor. ${ }^{5}{ }^{13} 14$

Prompted by recent reports by several groups showing that mice with Tbxl haploinsufficiency - which is located within the DiGeorge/VCFS region in 22q11.2-have cardiovascular defects, ${ }^{15-18}$ we investigated whether mutations, variants, or common haplotypes within the remaining TBXI gene could modify the expression of the heart phenotype in patients with $22 \mathrm{q} 11.2$ deletion.

\section{METHODS}

\section{Patients}

Our initial study group (P1) consisted of 78 white patients with 22q11.2 deletion, of whom 66 had congenital heart defects, and who were recruited from the paediatric cardiology centres of Erlangen and Tuebingen (southern Germany) (HP1); and 12 patients with normal hearts or with clinically non-relevant persistent arterial duct or persistent foramen ovale only, who were recruited from the Erlangen genetic clinic (NP1). Our confirmatory study group comprised 96 patients with 22q11.2 deletion recruited from the

\section{Key points}

- Although a common trait, the manifestation of congenital heart defects in 22q11.2 deleted patients is variable. To understand the basis for this, we examined the sequence of the remaining TBX1 allele as a strong candidate for congenital heart defects in patients with hemizygous 22q11.2 deletions.

- We detected 16 sequence variants, seven of which turned out to represent common SNPs. None of the variants showed a significant difference in frequencies between 22q11.2 deletion patients with and without congenital heart defects or normal controls. Nevertheless, a 9 bp deletion $\triangle$ AGG379-381, which was neither detected in non-congenital heart defect patients nor in normal controls, was found to segregate with ventricular septal defect (VSD) in one family. A causative role could also not be excluded for rare variants, which occurred in congenital heart defect patients only.

- 14 further sequence variants were detected, seven of which represented common single nucleotide polymorphisms. None of these variants affected a conserved nucleotide or differed in frequency between patients with and without congenital heart defects and the normal controls.

- To evaluate whether a certain haplotype or undetected common non-coding sequence variant could act as a modifier, the linkage disequilibrium structure of the TBX1 coding region was established. Using a combined approach with pairwise LD calculation and analysis of background haplotypes of rare variants, a reliable haplotype structure was defined, consisting of three LD blocks within the coding region and a further one beginning within the $5^{\prime}$ UTR.

- Association testing with each common haplotype as well as haplotype combinations revealed no difference between patients with and without congenital heart defects. Thus common TBXI variants were excluded as modifiers of the expression of congenital heart defects in patients with $22 \mathrm{q} 11.2$ deletion.

Abbreviations: DGS/VCFS, DiGeorge or velocardiofacial syndrome; GOLD, graphical package for overview of linkage disequilibrium; LD, linkage disequilibrium; PHASE, soffware package for phylogenetics and sequence evolution; SNP, single nucleotide polymorphism 
medical centre of Leuven, Belgium (P2), of whom 57 had a congenital heart defect (HP2) and 39 did not (NP2) (table 1). Our normal control group consisted of 96 healthy, dizygous individuals of north European origin.

The study was approved by the University of ErlangenNuremberg ethics review board and appropriate informed consent was obtained from human subjects.

\section{Procedures}

Sequencing was undertaken after polymerase chain reaction (PCR) amplification with intronic primers of all coding exons from the three different splice variants of $T B X 1$, and in addition of the $5^{\prime}$ UTR exon 1 on capillary sequencers (ABI $3100,3730)$. Primers for exons 2 (" $\left.1 \mathrm{~F}, 1 \mathrm{R}^{\prime}\right)$ and $9 \mathrm{a}($ ("7F, $8 \mathrm{R}^{\prime \prime}$ ) were used, as reported by Chieffo et al. ${ }^{19}$ Primer sequences for exons 4, 5, 6, 7/8, and 9c were kindly provided by Peter Scambler. Primers for exons 1, 3, and 9b were generated with primer $3^{20}$ and are as follows: tbxlaFGAGCAGATGTCTCAGCCCAG, tbxlaR-CCACACTCCTCTTC ACCTGC, tbx3bF-CACGCAGCTCTCGCATTTCT, tbx3bR-GAT AGGTGTTAGGAGGGGAG, tbx9bF-AGGCCACAAACACTTT GACC, and tbx9bR-TTCCATCACAGCCTCTTCAC. For P2 and normal controls, exons 2, 4, and 9a were co-amplified with a multiplex PCR kit (Qiagen, Hilden, Germany). Sequencing results were compared with the sequence from cosmid clone 91c (AC000091), now included within the RefSeq sequence NM 005992. In dizygous controls, haplotype structure was determined using PHASE. ${ }^{21}$ Linkage disequilibrium (LD) was calculated with $\mathrm{ld}_{\max }$ using an expectation-maximisation algorithm $^{22}$ and visualised with GOLD. ${ }^{23}$ Frequencies were compared by $\chi^{2}$ testing (Pearson) or by Fisher's exact test.

\section{RESULTS}

In study group Pl we detected 14 different sequence variants, seven of which had a frequency of 0.10 and above (table 2). All but the $\triangle$ AGG379-381 and V107V variants were detected in similar frequencies in normal controls. The $\Delta$ AGG379-381 variant was detected in a baby girl with a large subpulmonary ventricular septal defect (VSD), who inherited the 9 base pair (bp) deletion from her father, who also had a VSD but no 22q11.2 deletion. The V107V variant was found in a boy with pulmonary atresia-VSD; he inherited the deletion 22q11.2 from his mother, who had neither a congenital heart defect nor a TBXI variant. The father of this patient was not available. The V107V variant is located four nucleotides $5^{\prime}$ to the T-box and turned out to be the only one that affects a conserved nucleotide and amino acid (conserved in Mus

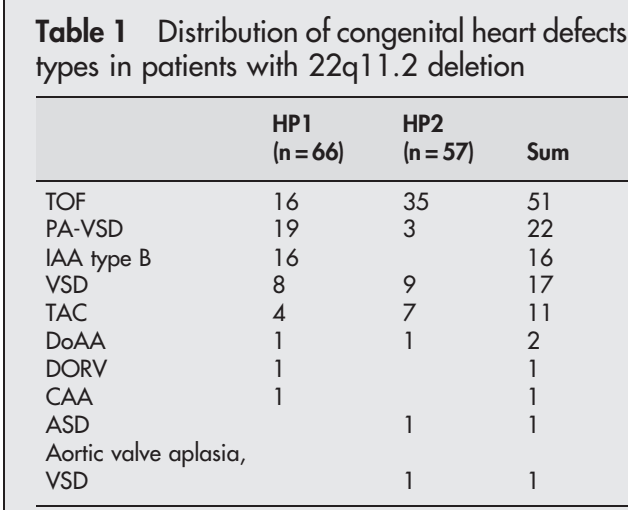

ASD, atrial septal defect; CAA, cervical aortic arch; DoAA, double aortic arch; DORV, double outlet right ventricle; IAA, interrupted aortic arch; PA-VSD, pulmonary atresia with ventricular septal defect; TAC, truncus arteriosus communis; TOF, tetralogy of Fallot.

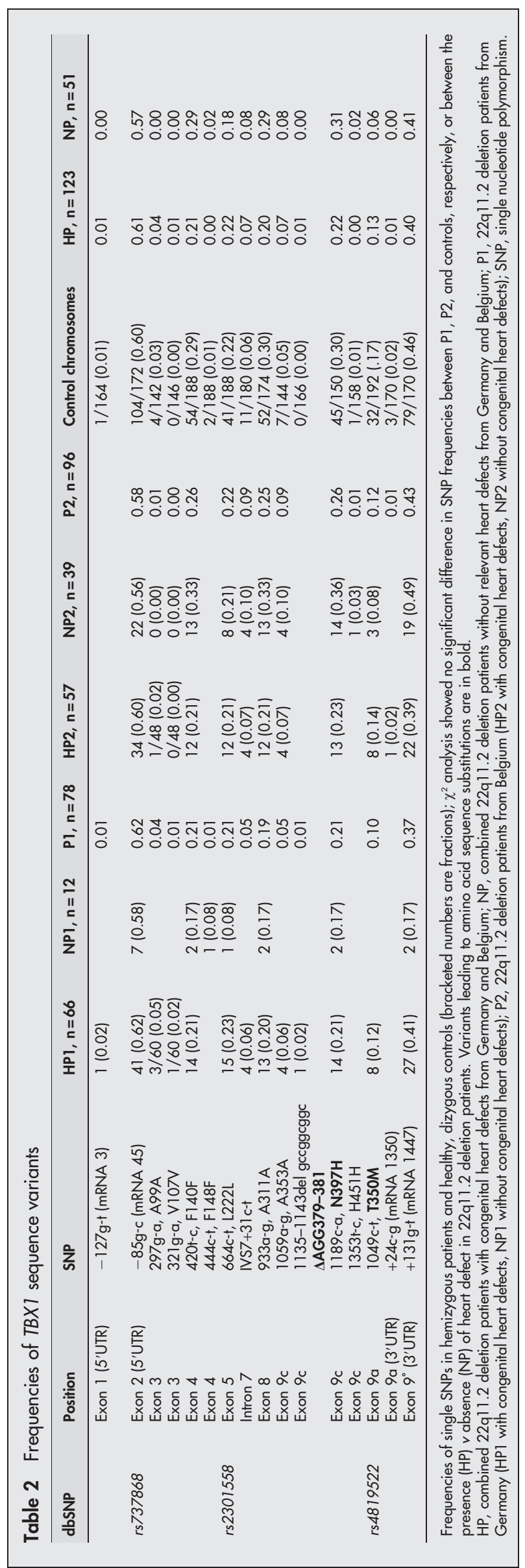




\section{Rare SNPs in relation to common haplotypes}

HP1 + 2 NP1 + 2 Controls

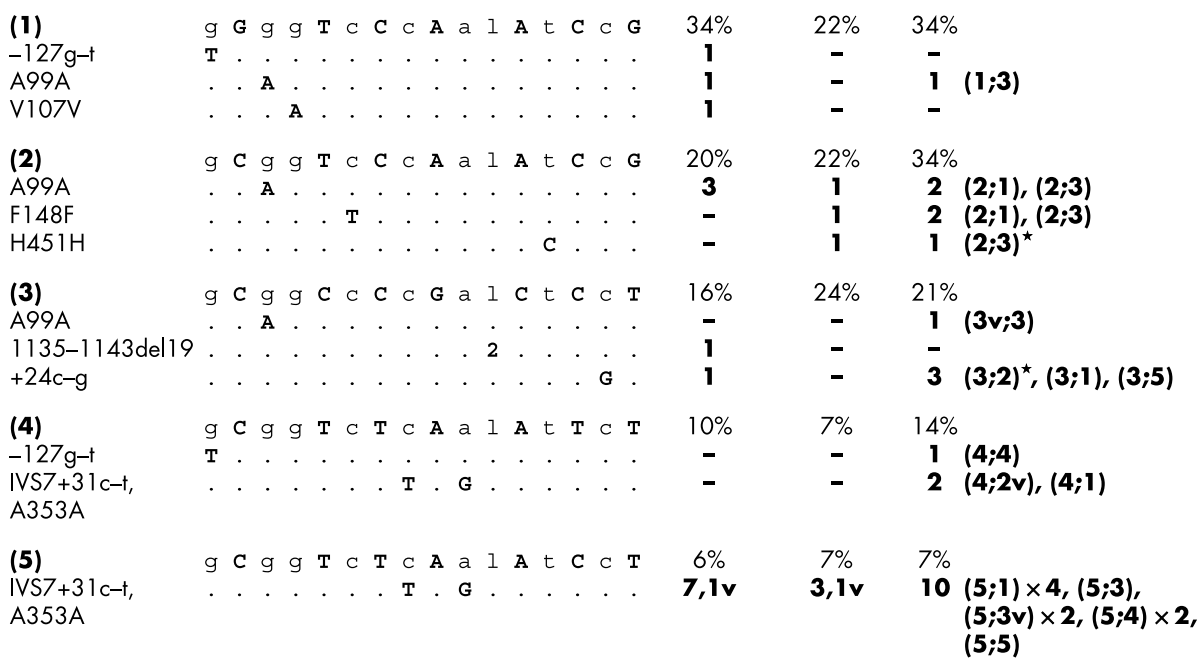

Figure 1 Position of rare variants on background haplotypes constructed from all observed single nucleotide polymorphisms (SNPs). The order of the SNPs is according to table 2 from exon 1 to 9 a. The frequency of the common haplotypes within different patient groups is given in per cent, alleles of common SNPs (>0.09) are written with bold capitals, wild type alleles of rare variants are written with small letters in the haplotype line. Numbers at the right side represent the number of patients in each group in whom a certain rare variant was observed on the respective background haplotype. As control persons are dizygous, both background haplotypes of each individual are given in parentheses. * Same individual. $v$, Variant of background haplotype.

musculus and Xenopus laevis, but not in Danio rerio or Drosophila melanogaster). The boy with the V107V variant is of local Franconian origin, as were the majority of the other patients in study group 1 and the normal controls.

As the haplotypes were naturally provided in these hemizygous individuals, we initially simply determined haplotype frequencies, grouping all seven common SNPs together. This showed that only five common haplotypes accounted for $93 \%$ of the chromosomes within our patient group Pl (fig 1), which would be within the commonly observed numbers for single haplotype blocks. ${ }^{24}$ To enhance the statistical power we analysed a further 96 hemizygous patients in whom we detected two further SNPs, and 96 dizygous healthy controls. Increasing the haplotype information from 78 to 174 hemizygous individuals reduced the incidence of the five common haplotypes to $85.6 \%$ of chromosomes. Reassessment of LD structure revealed a total of three LD blocks within the coding region and one starting with the 5'UTR region of exon 1 (table 3, figs 2 and 3 ).

Comparison of the frequencies of single SNPs and common haplotypes between groups P1 and P2, showed no significant difference; we therefore concluded that we can merge Pl and P2 without bias from ethnic background. There was no significant difference in frequencies of variants or common haplotypes between group HP (123 combined patients with $22 \mathrm{q} 11.2$ deletion and congenital heart defects) and group NP (5l combined patients with 22q11.2 deletion without relevant congenital heart defects) (tables 2 and 4). As the majority of patients were young children recruited through cardiology, the frequency of other malformations such as cleft palate was too low to undertake association studies. The same holds true for later onset symptoms such as psychiatric disease, which could not be assessed in this patient group.

\section{DISCUSSION}

We detected 16 sequence variants within the remaining TBXI copy in 174 deleted patients, of which only three were recorded in dbSNP; thus seven turned out to be common, with a frequency of 0.10 and above (table 2). None of the seven common or the nine rare variants with a frequency of $<0.10$ showed a significant difference between deletion patients with and without congenital heart defects or the
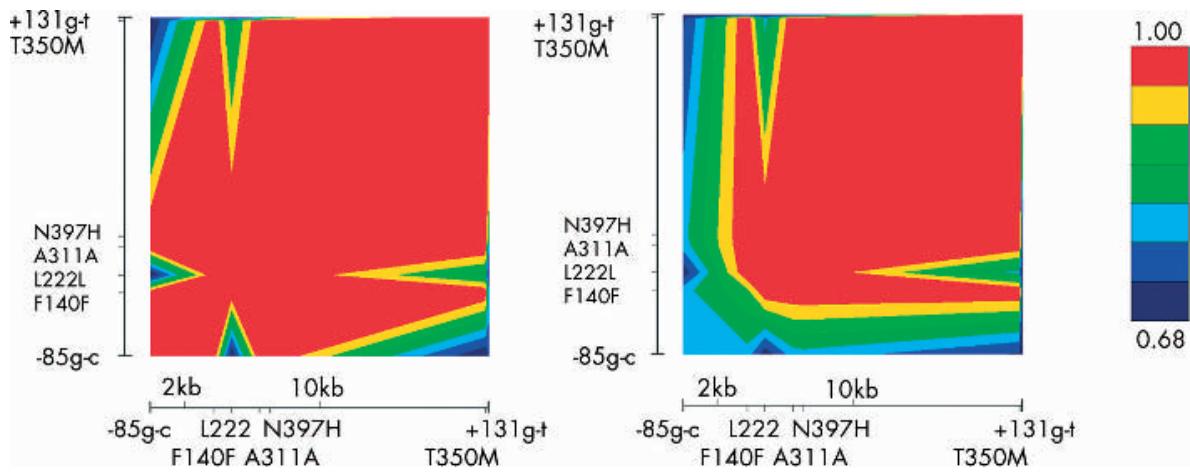

Figure 2 GOLD graphical overview of linkage disequilibrium for seven common TBX1 single nucleotide polymorphisms with naturally given haplotype data from (left) 78 and (right) 174 hemizygous patients. 


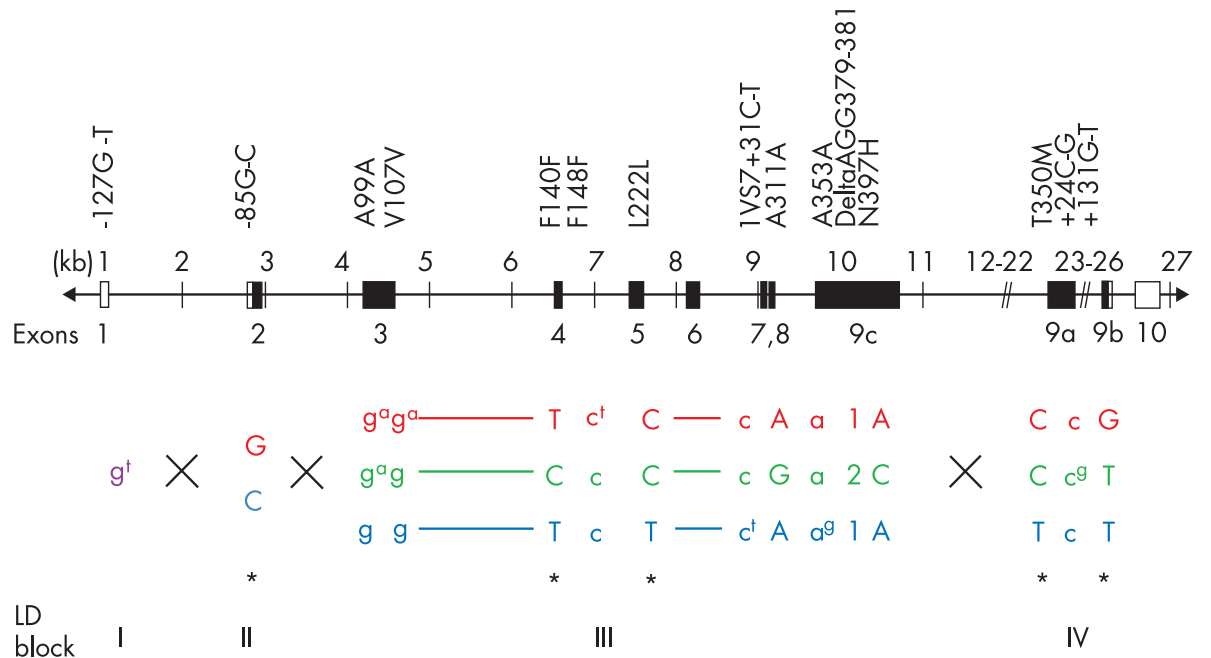

Figure 3 Schematic overview of linkage disequilibrium (LD) organisation of TBX1. LD blocks are separated by black crosses. Common SNPs (frequency >0.09) are in bold. Exon 1 (5'UTR) belongs to LD block I of unknown size, exon 2 (5'UTR) belongs to an LD block with maximum size of about $3 \mathrm{~kb}$, exons 3 to $9 \mathrm{c}-$ covering at least $6 \mathrm{~kb}$-constitute the core LD block III, with three common haplotypes accounting for $98.4 \%$ of 366 chromosomes; and exon 9a represents LD block IV of unknown size with at least three common haplotypes accounting for $100 \%$ of 366 chromosomes. Haplotypes of defined blocks were each observed in combination with every haplotype from neighbouring blocks, but most frequent combinations are equally coloured. Block II haplotype 2 was only observed once in 366 chromosomes in combination with haplotype 3 from block III. *Haplotype tag SNP.

Table 3 LD calculation for the seven common SNPs (frequency $>0.09$ )

\begin{tabular}{|c|c|c|c|c|c|c|c|c|c|}
\hline MI & M2 & P1 & $\chi^{2}$ & $\mathrm{p}$ Value & $\mathbf{D}^{\prime}$ & $\mathrm{P} 1+\mathrm{P} 2$ & $\chi^{2}$ & $\mathrm{p}$ Value & $\mathbf{D}^{\prime}$ \\
\hline 1 & 2 & 79 & 35.42 & 0.00000 & 1.000 & 170 & 46.78 & 0.00000 & 0.798 \\
\hline 1 & 3 & 79 & 12.58 & 0.00039 & 0.671 & 170 & 28.54 & 0.00000 & 0.692 \\
\hline 1 & 4 & 79 & 32.86 & 0.00000 & 1.000 & 169 & 45.24 & 0.00000 & 0.794 \\
\hline 1 & 5 & 78 & 33.49 & 0.00000 & 1.000 & 169 & 47.41 & 0.00000 & 0.799 \\
\hline 1 & 6 & 79 & 5.68 & 0.01714 & 0.671 & 170 & 15.28 & 0.00009 & 0.716 \\
\hline 1 & 7 & 79 & 33.24 & 0.00000 & 0.728 & 170 & 68.23 & 0.00000 & 0.683 \\
\hline 2 & 3 & 79 & 16.43 & 0.00005 & 1.000 & 174 & 45.45 & 0.00000 & 1.000 \\
\hline 2 & 4 & 79 & 138.63 & 0.00000 & 1.000 & 173 & 360.03 & 0.00000 & 1.000 \\
\hline 2 & 5 & 78 & 152.74 & 0.00000 & 1.000 & 173 & 383.55 & 0.00000 & 1.000 \\
\hline 2 & 6 & 79 & 7.69 & 0.00556 & 1.000 & 174 & 22.44 & 0.00000 & 1.000 \\
\hline 2 & 7 & 79 & 45.30 & 0.00000 & 0.802 & 174 & 87.98 & 0.00000 & 0.721 \\
\hline 3 & 4 & 79 & 15.27 & 0.00009 & 1.000 & 173 & 44.52 & 0.00000 & 1.000 \\
\hline 3 & 5 & 78 & 15.52 & 0.00008 & 1.000 & 173 & 45.80 & 0.00000 & 1.000 \\
\hline 3 & 6 & 79 & 39.20 & 0.00000 & 0.843 & 174 & 83.27 & 0.00000 & 0.801 \\
\hline 3 & 7 & 79 & 34.05 & 0.00000 & 0.704 & 174 & 62.29 & 0.00000 & 0.675 \\
\hline 4 & 5 & 78 & 132.14 & 0.00000 & 1.000 & 173 & 360.03 & 0.00000 & 1.000 \\
\hline 4 & 6 & 79 & 7.15 & 0.00750 & 1.000 & 173 & 21.97 & 0.00000 & 1.000 \\
\hline 4 & 7 & 79 & 40.22 & 0.00000 & 0.789 & 173 & 85.06 & 0.00000 & 0.716 \\
\hline 5 & 6 & 78 & 7.26 & 0.00706 & 1.000 & 173 & 22.60 & 0.00000 & 1.000 \\
\hline 5 & 7 & 78 & 52.88 & 0.00000 & 0.894 & 173 & 89.67 & 0.00000 & 0.723 \\
\hline 6 & 7 & 79 & 35.28 & 0.00000 & 1.000 & 174 & 76.29 & 0.00000 & 1.000 \\
\hline
\end{tabular}

normal control group, respectively. However, two of the rare variants-1135-1143delgccggcggc (DAGG379-381) and $32 \lg$-a (V107V) - were not detected in patients without congenital heart defects or in healthy controls. Thus it is likely that the $9 \mathrm{bp}$ deletion at least contributes to the heart phenotype, as it segregated with VSD in one family. The $32 \mathrm{lg}-\mathrm{a}(\mathrm{V} 107 \mathrm{~V})$ variant turned out to be the only one that affects a conserved nucleotide and might therefore also represent a relevant mutation, as synonymous changes can affect splicing. As TBXI is not expressed in blood, splicing could not be tested in this patient. Nevertheless, even if the $9 \mathrm{bp}$ deletion and V107V, respectively, are considered relevant contributors to the expression of congenital heart defects, TBXI variants would still account for only $1.6 \%$ of cases of congenital heart disease in 22q11.2 deletion patients.
However, functional studies are necessary to confirm the impact of these rare variants.

To further evaluate whether there were haplotypes or common non-coding sequence variants not detected in our

\section{Electronic database information}

- Online Mendelian Inheritance in Man (OMIM): http:// www.ncbi.nlm.nih.gov/Omim/.

- Locus Link: http://www.ncbi.nlm.nih.gov/LocusLink/.

- Single nucleotide polymorphism data base (dbSNP): http://www.ncbi.nlm.nih.gov/SNP/. 
Table 4 Frequency of different haplotypes within single linkage disequilibrium (LD) blocks, and analysis of association between each LD block haplotype and congenital heart defects in deletion patients

\begin{tabular}{|c|c|c|c|c|c|c|c|}
\hline $\begin{array}{l}\text { LD } \\
\text { block }\end{array}$ & Haplotype & $\begin{array}{l}\text { Controls } n=192 \\
\text { chromosomes }^{*}\end{array}$ & $\begin{array}{l}\mathrm{Pl}, \\
\mathrm{n}=78\end{array}$ & $\begin{array}{l}\mathrm{P2} \\
\mathrm{n}=96\end{array}$ & $H P, n=123$ & $N P, n=51$ & $\chi^{2}$ HP v NP \\
\hline III & $\begin{array}{l}1 \\
2 \\
3\end{array}$ & $\begin{array}{l}0.48 \\
0.27 \\
0.21\end{array}$ & $\begin{array}{l}0.59 \\
0.19 \\
0.21\end{array}$ & $\begin{array}{l}0.52 \\
0.27 \\
0.21\end{array}$ & $\begin{array}{l}70=0.57 \\
25=0.20 \\
27=0.22\end{array}$ & $\begin{array}{l}26=0.51 \\
16=0.31 \\
9=0.18\end{array}$ & $\begin{array}{l}0.51(p=0.475) \\
2.44(p=0.118) \\
0.41(p=0.522)\end{array}$ \\
\hline IV & $\begin{array}{l}1 \\
2 \\
3\end{array}$ & $\begin{array}{l}0.53 \\
0.30 \\
0.16\end{array}$ & $\begin{array}{l}0.63 \\
0.27 \\
0.10\end{array}$ & $\begin{array}{l}0.57 \\
0.31 \\
0.11\end{array}$ & $\begin{array}{l}74=0.60 \\
33=0.27 \\
16=0.13\end{array}$ & $\begin{array}{l}30=0.59 \\
18=0.35 \\
3=0.06\end{array}$ & $\begin{array}{l}0.18(p=0.671) \\
1.25(p=0.264) \\
1.88(p=0.170)\end{array}$ \\
\hline I-IV & $\begin{array}{l}\text { (1) } \\
\text { (2) } \\
(3) \\
(4) \\
(5)\end{array}$ & $\begin{array}{l}0.34 \\
0.14 \\
0.21 \\
0.14 \\
0.07\end{array}$ & $\begin{array}{l}0.35 \\
0.26 \\
0.17 \\
0.09 \\
0.06\end{array}$ & $\begin{array}{l}0.27 \\
0.21 \\
0.20 \\
0.08 \\
0.06\end{array}$ & $\begin{array}{l}41=0.34 \\
25=0.20 \\
20=0.16 \\
12=0.10 \\
7=0.06\end{array}$ & $\begin{array}{l}11=0.22 \\
15=0.29 \\
12=0.24 \\
3=0.07 \\
3=0.07\end{array}$ & $\begin{array}{l}\text { 2. } 38(p=0.123) \\
1.68(p=0.195) \\
1.27(p=0.260)\end{array}$ \\
\hline
\end{tabular}

*Frequency of different haplotypes within single LD blocks in 96 healthy, dizygous controls; $\chi^{2}$ analysis showed no significant association between single haplotypes or haplotype combinations (IIIV) and the presence of heart defects in 22q11.2 deletion patients. Values of $\chi^{2}$ could not be determined for variations (4) and (5) in combined haplotypes I-IV, as the expected cell frequencies are less than five. However, there is obviously no significant difference in frequency. Differences of haplotype frequencies between controls, P1 and P2, respectively are also not significant. Numbering of haplotypes is as in fig 3 for LD block III and IV, and as in fig 1 for combined LD blocks. HP, combined 22q11.2 deletion patients with congenital heart defects from Germany and Belgium; NP, combined 22q11.2 deletion patients without relevant heart defects from Germany and Belgium; $\mathrm{Pl}, 22 \mathrm{q} 11.2$ deletion patients from Germany; P2, 22q11.2 deletion patients from Belgium.

scan that could act as modifiers, we investigated whether certain haplotypes might influence the expression of the heart phenotype. As the haplotype structure of the TBXI locus had not been analysed before, we first had to determine LD blocks. Definition of LD blocks aims to identify genomic regions where a few unique haplotypes are distributed widely throughout the population, but the methods are still subjective; some approaches make use of known or inferred haplotypes, others use pairwise LD measures, and yet others use a combination of the two. ${ }^{25}{ }^{26}$ In contrast to analysis of haplotype structure in dizygous individuals, haplotype construction in our patients is not hampered by likelihood assumptions as they are hemizygous, thus providing naturally given haplotype information. Although in our initial study group, grouping of all seven common SNPs together into one LD block resulted in only five common haplotypes, accounting for $93 \%$ of chromosomes, expanding the patient group from 78 to 174 hemizygous individuals reduced the incidence of the five common haplotypes to $85.6 \%$ of chromosomes, which suggests the existence of more than one LD block. ${ }^{24}$ This observation is in line with the recommendation that at least 100 chromosomes should be used in haplotype block studies. ${ }^{27}$ Moreover, with the "one LD block only" definition, several recurrent rare variants would have occurred on different haplotypes (fig 1), which we assumed was unlikely-especially for variants IVS7+31c-t and A353A, which always occurred together. When we postulated that the combination of these two SNPs appeared only once, the core ancestral haplotype block would only consist of four common SNPs (fig 3). Under this assumption, all but one rare variant would have occurred only on one haplotype each, and $\mathrm{D}^{\prime}$ values would be 1.0 for each SNP pair comparison within the blocks (table 3 ). By this approach only three different haplotypes occur within each LD block, so our definition is in line with the four gamete test definition. ${ }^{27}$ Despite the complete pairwise LD for block III, SNP A99A occurred eight times on haplotype 1 and once on haplotype 2. However, as this SNP affects an CpG doublet, an independent origin is likely. As $\mathrm{D}^{\prime}$ values confining haplotype blocks are still arbitrary and differ widely in different studies, ${ }^{28}{ }^{29}$ it is noteworthy that common SNP 6 (T350M), which does not belong to the core block III under our definition, is also in complete LD with all but one SNP $(3=\mathrm{L} 222 \mathrm{~L})$ from this block (table 3). Our study also shows that PHASE is able to produce the same haplotype distributions by likelihood calculation in dizygous individuals as in our naturally phased hemizygous patients.

As haplotype distribution was equal for all groups (table 4), we were able to exclude an influence of undetected intronic variants residing on common haplotypes of TBXI on expression of the heart phenotype in patients with 22q11.2 deletion. Thus our results show that variants within the TBXI region are not common modifiers of heart phenotype in patients with deletion 22q11.2. However, as we found that the $5^{\prime}$ promotor region is located on a different haplotype block, it is still possible that common variants within the $T B X 1$ promotor region, recently shown to span about $15 \mathrm{~kb},{ }^{30}$ could influence the manifestation of congenital heart defects in DGS/VCFS patients.

As a strong candidate for a major contributor to the DGS/ VCFS phenotype, ${ }^{15-18} 31-33$ TBXI has been analysed previously for mutations in non-deleted DGS/VCFS patients. Splice variant A (including alternative exon 9a) has been sequenced in 16 patients, but only five of seven common polymorphisms were identified. ${ }^{19}$ Splice variant $C$ (including alternative exon 9c) was analysed in 105 non-deleted patients, of whom 40 had clinical features of DGS/VCFS and 65 had isolated cardiac lesions frequently seen in DGS/VCFS. ${ }^{34}$ In the latter study, eight common polymorphisms were reported, of which six are identical with four common and two less common variants, with the frequencies of 0.04 to 0.05 seen in our study. However, it is likely that the two further variants reported as $-75 \mathrm{~g}-\mathrm{c}$ and IVS $7+46$ are probably also identical with our common SNPs $-85 \mathrm{~g}-\mathrm{c}$ and IVS7+31c-t, respectively. This assumption is supported by the fact that in our study IVS7+31c-t always occurred together with A353A, which also seems to be the case for A353A and "IVS7+46", because they appeared with exactly the same incidence. Gong et al also detected 10 rare variants, including amino acid exchanges, deletions, and duplications - nine of which were not seen in 101-139 controls. ${ }^{34}$ However, the clinical relevance of these rare variants is not proven as all patients whose parents were 
available inherited the rare variant from a healthy parent. Conti et al analysed all three different TBXI splice variants in 41 patients with non-syndromic cono-truncal heart defects for mutations by SSCP analysis, and detected five of our common SNPs as well as two novel variants (exon 9c 1022ca, normal population frequency $1 \%$; exon 10B 3'UTR mRNA position $1486 \mathrm{c}-\mathrm{a}$, normal population frequency $10.5 \%){ }^{35}$ These investigators concluded that with a multifactorial model for congenital heart defects they cannot rule out the possibility that these rare or common variants are somehow involved in the pathogenesis of the patients' heart malformations. However, they made no attempt to carry out an association study.

Our nine rare variants were not seen in 162 non-deleted patients analysed by the other groups, and we did not see any of the 10 rare variants reported by them ${ }^{34}$ in our 174 hemizygous patients. Although this might just reflect the low incidence of these variants, we cannot exclude the possibility that, in particular, the frameshift variants detected in non-deleted DGS/VCFS/congenital heart defects patients could be lethal in our hemizygous patients, as early lethality has been shown for double mutant mice..$^{15-17}$

With respect to further association studies our results show that exon 3 to 9c, covering at least $6 \mathrm{~kb}$, constitute a single core LD block, with three common haplotypes accounting for $98.36 \%$ of 366 chromosomes (block III), while exons 1, 2, and 9a are parts of different LD blocks (I, II, and IV, respectively). Thus typing of at least five haplotype tag SNPs is necessary to cover the common haplotype structure of the $27 \mathrm{~kb}$ region of $T B X 1$, which is in line with the assumption from a first chromosome $22 \mathrm{LD}$ map with $15 \mathrm{~kb}$ SNP spacing that the DGS/VCFS region shows low LD, and thus fine mapping for any association might require a high density of markers. ${ }^{28}$

\section{ACKNOWLEDGEMENTS}

This study was supported by the Deutsche Forschungsgemeinschaft grant RA833/4-1 to AR. We are grateful to Brigitte Dintenfelder for excellent technical assistance and to the families for their kind cooperation. KD \& MG are supported by the Belgian Foundation for Research in Paediatric Cardiology. KD is a senior clinical investigator of the FWO-Vlaanderen.

\section{Authors' affiliations \\ A Rauch, C Kraus, A Reis, Institute of Human Genetics, Friedrich- Alexander University Erlangen-Nuremberg, Germany \\ K Devriendt, Centre for Human Genetics, Leuven, Belgium \\ A Koch, H Singer, Department of Paediatric Cardiology, Friedrich- Alexander University Erlangen-Nuremberg, Germany \\ R Rauch, M Hofbeck, Department of Pediatric Cardiology, University of Tvebingen, Germany \\ M Gewillig, Paediatric Cardiology, Leuven, Belgium \\ M Weyand, Department of Heart Surgery of the Friedrich-Alexander \\ University Erlangen-Nuremberg \\ Competing interests: none declared}

Correspondence to: Dr Anita Rauch, Institute of Human Genetics, Schwabachanlage 10, 91054 Erlangen, Germany; arauch@humgenet. uni-erlangen.de

Received 3 June 2003

Accepted for publication 5 September 2003

\section{REFERENCES}

1 Wilson DI, Cross IE, Wren C. Minimum prevalence of chromosome 22q1 1 deletions [abstract]. Am J Hum Genet 1994;55:A169.

2 Carlson C, Sirotkin H, Pandita R, Goldberg R, McKie J, Wadey R, Patanjali SR, Weissman SM, Anyane-Yeboa K, Warburton D, Scambler P, Shprintzen R, Kucherlapati R, Morrow BE. Molecular definition of 22q11 deletions in 151 velo-cardio-facial syndrome patients. Am J Hum Genet 1997;61:620-9.

3 Fryer A. Monozygotic twins with 22q11 deletion and discordant phenotypes. J Med Genet 1996;33:173.
4 Goodship J, Cross I, P S, Burn J. Monozygotic twins with chromosome 22q1 1 deletion and discordant phenotype. J Med Genet 1995;32:746-8.

5 Hatchwell E. Monozygotic twins with chromosome 22q11 deletion and discordant phenotype. J Med Genet 1996;33:261.

6 Lu JH, Chung MY, Hwang B, Chien HP. Monozygotic twins with chromosome $22 \mathrm{~g} 11$ microdeletion and discordant phenotypes in cardiovascular patterning. Pediatr Cardiol 2001;22:260-3.

7 Vincent MC, Heitz F, Tricoire J, Bourrouillou G, Kuhlein E, Rolland M, Calvas P. $22 q 11$ deletion in DGS/VCFS monozygotic twins with discordant phenotypes. Genet Couns 1999;10:43-9.

8 Yamagishi H, Ishii C, Maeda J, Kojima Y, Matsuoka R, Kimura M, Takao A, Momma K, Matsuo N. Phenotypic discordance in monozygotic twins with 22q11.2 deletion. Am J Med Genet 1998;78:319-21.

9 Taddei I, Morishima M, Huynh T, Lindsay EA. Genetic factors are major determinants of phenotypic variability in a mouse model of the DiGeorge/ del22q1 1 syndromes. Proc Natl Acad Sci USA 2001;98:11428-31.

10 Vitelli F, Taddei I, Morishima M, Meyers EN, Lindsay EA, Baldini A. A genetic link between $\mathrm{Tbxl}$ and fibroblast growth factor signaling. Development 2002; 129:4605-11.

11 Rauch A, Hofbeck M, Cesnjevar R, Koch A, Rauch R, Buheitel G, Singer H, Weyand $M$. Search for somatic 22q1 1.2 deletions in patients with conotruncal heart defects. Am J Med Genet 2004; 124:165-9.

12 Stalmans I, Lambrechts D, De Smet F, Jansen S, Wang J, Maity S, Kneer P, Von Der Ohe M, Swillen A, Maes C, Gewillig M, Molin DG, Hellings P, Boetel T, Haardt $M$, Compernolle V, Dewerchin M, Plaisance $S$, Vlietinck R, Emanuel B, Gittenberger-De Groot AC, Scambler P, Morrow B, Driscol DA, Moons L, Esguerra CV, Carmeliet G, Behn-Krappa A, Devriendt K, Collen D, Conway SJ, Carmeliet P. VEGF: a modifier of the del22q1 1 (DiGeorge) syndrome? Nat Med 2003;9:173-82.

13 Hall JG. CATCH 22. J Med Genet 1993;30:801-2.

14 Dallapiccola B, Pizzuti A, Novelli G. How many breaks do we need to CATCH on 22q11? Am J Hum Genet 1996;59:7-11.

15 Lindsay EA, Vitelli F, Su $H$, Morishima M, Huynh T, Pramparo T, Jurecic V, Ogunrinu G, Sutherland HF, Scambler PJ, Bradley A, Baldini A. Tbx 1 haploinsufficieny in the DiGeorge syndrome region causes aortic arch defects in mice. Nature 2001;410:97-101.

16 Merscher S, Funke B, Epstein JA, Heyer J, Puech A, Lu MM, Xavier RJ Demay MB, Russell RG, Factor S, Tokooya K, Jore BS, Lopez M, Pandita RK, Lia M, Carrion D, Xu H, Schorle H, Kobler JB, Scambler P, Wynshaw-Boris A, Skoultchi Al, Morrow BE, Kucherlapati R. TBX1 is responsible for cardiovascular defects in velo-cardio-facial/DiGeorge syndrome. Cell 2001; 104:619-29.

17 Jerome LA, Papaioannou VE. DiGeorge syndrome phenotype in mice mutant for the T-box gene, Tbx1. Nat Genet 2001;27:286-91

18 Vitelli F, Morishima M, Taddei I, Lindsay EA, Baldini A. Tbx 1 mutation causes multiple cardiovascular defects and disrupts neural crest and cranial nerve migratory pathways. Hum Mol Genet 2002;11:915-22.

19 Chieffo C, Garvey N, Gong W, Roe B, Zhang G, Silver L, Emanuel BS, Budarf ML. Isolation and characterization of a gene from the DiGeorge chromosomal region homologous to the mouse Tbxl gene. Genomics 1997:43:267-77

20 Rozen S, Skaletsky HJ. Primer3 on the WWW for general users and for biologist programmers, in Bioinformatics methods and protocols: methods in molecular biology. In: Krawetz S, Misener S, eds. Totowa, NJ: Humana Press, 2000:365-86.

21 Stephens M, Smith NJ, Donnelly P. A new statistical method for haplotype reconstruction from population data. Am J Hum Genet 2001;68:978-89.

22 Excoffier L, Slatkin M. Maximum-likelihood estimation of molecular haplotype frequencies in a diploid population. Mol Biol Evol 1995;12:921-7.

23 Abecasis GR, Cookson WO. GOLD - graphical overview of linkage disequilibrium. Bioinformatics 2000;16:182-3.

24 Gabriel SB, Schaffner SF, Nguyen H, Moore JM, Roy J, Blumenstiel B, Higgins J, DeFelice $M$, Lochner A, Faggart $M$, Liu-Cordero SN, Rotimi C, Adeyemo A, Cooper R, Ward R, Lander ES, Daly MJ, Altshuler D. The structure of haplotype blocks in the human genome. Science 2002;296:2225-9.

25 Daly MJ, Rioux JD, Schaffner SF, Hudson TJ, Lander ES. High-resolution haplotype structure in the human genome. Nat Genet 2001;29:229-32.

26 Cardon LR, Abecasis GR. Using haplotype blocks to map human complex trait loci. Trends Genet 2003; 19:135-40.

27 Wang N, Akey JM, Zhang K, Chakraborty R, Jin L. Distribution of recombination crossovers and the origin of haplotype blocks: the interplay of population history, recombination, and mutation. Am J Hum Genet 2002;71:1227-34

28 Dawson E, Abecasis GR, Bumpstead S, Chen Y, Hunt S, Beare DM, Pabial J, Dibling $T$, Tinsley E, Kirby S, Carter D, Papaspyridonos M, Livingstone $S$ Ganske R, Lohmussaar E, Zernant J, Tonisson N, Remm M, Magi R, Puurand T, Vilo J, Kurg A, Rice K, Deloukas P, Mott R, Metspalu A, Bentley DR, Cardon LR, Dunham I. A first-generation linkage disequilibrium map of human chromosome 22. Nature 2002:418:544-8.

29 Phillips MS, Lawrence R, Sachidanandam R, Morris AP, Balding DJ, Donaldson MA, Studebaker JF, Ankener WM, Alfisi SV, Kuo FS, Camisa AL, Pazorov V, Scott KE, Carey BJ, Faith J, Katari G, Bhatti HA, Cyr JM, Derohannessian V, Elosua C, Forman AM, Grecco NM, Hock CR, Kuebler JM, Lathrop JA, Mockler MA, Nachtman EP, Restine SL, Varde SA, Hozza MJ, Gelfand CA, Broxholme J, Abecasis GR, Boyce-Jacino MT, Cardon LR. Chromosome-wide distribution of haplotype blocks and the role of recombination hot spots. Nat Genet 2003;33:382-7.

30 Yamagishi H, Maeda J, Hu T, McAnally J, Conway SJ, Kume T, Meyers EN, Yamagishi C, Srivastava D. Tbxl is regulated by tissue-specific forkhead 
proteins through a common sonic hedgehog-responsive enhancer. Genes Dev 2003;17:269-81.

31 Lindsay EA. Chromosomal microdeletions: dissecting del22q11 syndrome. Nat Rev Genet 2001;2:858-68.

32 Scambler PJ. The $22 q 11$ deletion syndromes. Hum Mol Genet 2000;9:2421-6.

33 Schinke M, Izumo S. Deconstructing DiGeorge syndrome. Nat Genet 2001;27:238-40
34 Gong W, Gottlieb S, Collins J, Blescia A, Dietz H, Goldmuntz E, McDonaldMcGinn DM, Zackai EH, Emanuel BS, Driscoll DA, Budarf ML. Mutation analysis of TBX1 in non-deleted patients with features of DGS/VCFS or isolated cardiovascular defects. J Med Genet 2001;38:E45.

35 Conti E, Grifone N, Sarkozy A, Tandoi C, Marino B, Digilio MC, Mingarelli R, Pizzuti A, Dallapiccola B. DiGeorge subtypes of nonsyndromic conotruncal defects: evidence against a major role of TBX1 gene. Eur J Hum Genet 2003;11:349-51. 